\title{
Pembuatan Turbin Double Spherical Sebagai Upaya Memperbaiki Kinerja Turbin Spherical
}

\author{
Yusuf Dewantoro, Denny Surendra, Yanuar M \\ Jurusan Teknik Mesin, Politeknik Negeri Semarang \\ Jl. Prof. H. Sudarto, S.H., Tembalang, Kotak Pos 6199/SMS, Semarang 50329 \\ Telp. 7473417, 7466420 (Hunting), fax. 7472396
}

\begin{abstract}
Abstrak
Tujuan dari tugas akhir ini adalah pembuatan turbin spherical helix berbasis NACA 0016 dengan sudut putar sebesar $30^{\circ}$ dengan penambahan jumlah runner, memperbaiki kerangka uji, melakukan uji kinerja turbin air yang telah dibuat, menghitung kinerja turbin dengan runner single dan double dan melakukan analisa kinerja turbin. Selanjutnya akan melakukan pengujian dan melihat hasil kinerja efisiensi yang dihasilkan. Pengujian turbin air ini menggunakan variable turbin spherical dan turbin double spherical dengan variable uji berupa kecepatan aliranl,2 $\mathrm{m} / \mathrm{s}$,danl,4 $\mathrm{m} / \mathrm{s}$. Sedangkan parameter uji berupa putaran poros turbin, massa torsi, dan head. Data-data hasil pengujian selanjutnya diolah untuk mengetahui daya mekanik dan efisiensi turbin maksimum. Hasil pengujian ini menunjukkan bahwa efisiensi tertinggi yang mampu dihasilkan turbin spherical helix yaitu sebesar 20,9\% pada varibel uji pada kecepatan aliran kerja 1,2 m/s dengan putaran turbin $155 \mathrm{rpm}$, dan $21,21 \%$ pada variable uji pada kecepatan aliran kerja 1,4 m/s dengan putaran turbin $150 \mathrm{rpm}$. Sedangkan pada turbin double spherical helix mampu menghasilkan efisiensi yaitu sebesar 27,4\% pada variable uji pada kecepatan aliran kerja 1,2 m/s dengan putaran turbin $160 \mathrm{rpm}$, dan 33,02\% pada variable uji pada kecepatan aliran kerja 1,4 m/s dengan putaran turbin $170 \mathrm{rpm}$.
\end{abstract}

Kata kunci : Turbin air, Spherical, Helix Sudut 30º, Berbasis NACA 0016

\section{Pendahuluan}

Tenaga air merupakan sumber daya terpenting setelah uap atau panas.Hampir sebagian dari kebutuhan tenaga listrik di dunia dipenuhi oleh pusat-pusat pembangkit listrik tenaga air. Teknologi ini terdiri dari komponen utama yaitu turbin air dan generator listrik. Turbin air berperan untuk mengubah energi air (energi potensial, tekanan dan energi kinetik) menjadi energi mekanik dalam bentuk putaran poros. Putaran poros turbin ini akan diubah oleh generator menjadi tenaga listrik. Pemanfaatan air digunakan untuk menghasilkan energi ramah lingkungan dan terbarukan serta dapat dimanfaatkan oleh masyarakat.Pemanfaatan air sungai sebagai energi alternatif sering kali tidak teraplikasi secara maksimal, hal ini dikarenakan pengetahuan masyarakat dan prasarana yang kurang. Sebagai contoh pemanfaatan sungai irigasi, selain sebagai pengairan sawah, potensi alirannya juga bisa dimanfaatkan pada energi kinetiknya. Turbin yang cocok untuk memanfaatkan potensi air sungai atau air laut dikenal dengan turbin air aliran silang atauCross Flow Water Turbine
(CFWT). Beberapa turbin air yang sudah kita kenal antara lain Turbin Darrieus, Turbin Gorlov, Turbin Achard dan Maitre dan Turbin Zanette. Turbin-turbin tersebut

memiliki kelebihan dan kekurangan masingmasing untuk perairan diIndonesia.Model CFWT yang ada salah satunya adalah turbin Darrieus berbentuk sudu hydrofoil, poros vertikal dan jumlah sudu 3. Hasil pengembangan turbin Darrieus salah satunya adalah turbin Spherical . Turbin Spherical yang dibuat memiliki rasio panjang line chord dan diameter runner turbin 0.5. Hasil uji menunjukan turbin Spherical memiliki efisiensi yang lebih tinggi dibandingkan turbin Darrieus. Melalui Tugas akhir ini akan dilakukan perubahan dari jumlah runner satu buah menjadi dua buah (parallel) dalam satu poros turbin untuk mendapat kinerja yang lebih baik dari turbin Spherical.

\section{Turbin Aliran Silang}

Turbin air aliran silang atau Cross Flow Water Turbine (CFWT), memiliki sumbu rotasi tegak lurus terhadap arus. Jenis turbin 
ini memiliki beberapa keuntungan turbin beroperasi dalam segala arah aliran, namun desain dan prediksi perilaku hidro dinamikanya lebih rumit (Paraschivioiu I, 2002).

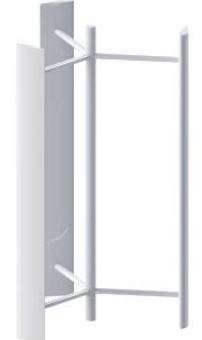

(a)

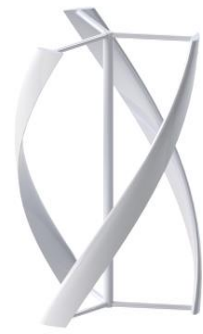

(b)

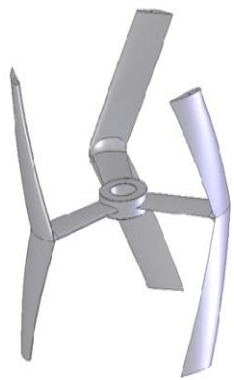

(c)
Gambar 1.1 Tiga Model CFWT dari skala yang berbeda (a) Darrieus,1931;

(b) Gorlov, 1997 ;

(c) Archard dan Maitre, 2004

Turbin aliran silang Cross Flow Water Turbine (CFWT) dikembangkan dari turbin Darrieus (1931) yang memanfaatkan energi angin sebagai fluida kerja. Desain Darrieus dapat dilihat pada Gambar 2.1a. sudu turbin Darrieus berjumlah 3 dan berpenampang airfoil yang dipasang tegak sejajar dengan poros turbin Darrieus. Desain Turbin Darrieus dikembangkan untuk fluida air oleh Gorlov o(1997). Perbedaan turbin Gorlov terletak pada arah posisi sudu. Jika sudu Darrieus memiliki arah posisi vertikal, pada turbin Gorlov memiliki arah posisi helik. Turbin - turbin tersebut kemudian dikembangkan dalam bentuk yang berbeda oleh Archard dan Maitre (2004), seperti pada gambar 2.1c suduturbin Archard Maitre berbentuk delta dengan luas penampang tetap/konstan.

\section{Pengembangan Turbin Darrieus}

Aliran air irigasi untuk pengairan pada sektor pertanian mempunyai energi kinetik yangdapat dimanfaatkan untuk menggerakkan turbin air. Jenis turbin aliran sungai yangcocok dipakai adalah turbin air Gorlov dan Darrieus. Turbin Darrieus mempunyaikeuntungan yaitu sudunya dapat dibuat dengan mudah (Winchester et al, 2009). Suduini memakai standard National Advisory Committee for Aeronautics (NACA) agar aliran disekitarnya tidak terjadi turbulensi apabilasudut masuk tidak besar.

Kedua turbin diatas telah mulai dimanfaatkan untuk menggerakkan generatorlistrik baik skala kecil maupun besar. Bila aliran sungai yang deras dan dengan debit yang besar maka akan dapat menghasilkan daya yang besar pula. Turbin Darrieus dan Gorlov mempunyai efisiensi yang rendah dibandingkan dengan turbin lainnya sepertijenis Pelton dan Francis yang penggunaannya untuk head yang tinggi. Ukuran dimensi turbin dapatdiperbesar atau dengan memasang turbin yang banyak untuk mendapatkan daya listrik yang besar.

Gorlov (2001) mengemukakan bahwa pemanfaatan energi aliran sungai untukpembangkitan energi listrik adalah salah satu usaha untuk mempercepat peningkatanpenggunaan sumber energi terbarukan. Pengembangan yang terus menerus, yangefisien, cenderung murah dan ramah lingkungan. Pada aliran head rendah (low head) dimanfaatkan turbin melengkung (helical) bersudu tiga yang dapat juga didayagunakan pada arus pasang surut.Turbin tersebut dapat membangkitkan multi megawatt dan dapat membangkitkan dalam skala beberapa kilowatt. Turbin Darrieus dan Gorlov mempunyai prinsip yang sama, akan tetapi turbin Darrieus mempunyai bentuk sudu lurus sedang Gorlov sudunya dalam bentuk heliks yang sulit dibuat.

Shiono et.al (2002) telah mempelajari secara eksperimental pengaruh soliditas,kecepatan air dan terhadapap kinerja turbin air Darrieus yang mempunyai tiga sududengan jenis sudu lurus dan heliks. Soliditas sangat kecil pengaruhnya terhadap kinerjaakan tetapi semakin besar soliditas maka turbin akan semakin turun putarannya atausebaliknya. Untuk kecepatan air yang yang berbeda maka akan semakin berubahkinerjanya yang 
mana apabila kecepatan air semakin tinggi maka semakin besarefisiensinya. Selain itu juga kemiringan (bentuk heliks) sudu atau sudu turbin Gorlovpada sudut heliks 43, $7^{\circ}$ mempunyai efisiensi yang paling tinggi dibanding dengansudut heliks lainnya yang mana efisiensi tertingginya adalah sekitar $15 \%$.

Kyozuka et al. (2006) memberikan pengaruh jumlah sudu dan jenis sudu taksimeris yang digunakan untuk mempelajari kenerjanya. Dari hasil studi eksperimentantersebut menunjukkan bahwa jumlah sudu tiga buah mempunyai sudu efisiensi yanglebih tinggi dibandingkan dengan jumlah sudu dua buah. Selain itu dengan bentukcamber lingkar memperbesar efisiensinya.

Antheaume, et.al (2007). Mengemukakan bahwa berdasarkan simulasi dan eksperimen diperoleh efisiensi maksimum untuk turbin Darrieus 23\%, turbin Gorlov35\% dan turbin Archad sebesar $39,4 \%$. Hal ini merupakan inovasi baru dalampengembangan turbin air poros vertikal dengan model helical blade.

Golechal et al.(2011) menggunakan prinsip pengarah aliran yang berupa pemantulan (deflector plate)untukmenaikkan efisiensi dari turbin air Savonius menjadi 35\% pada tip speed ratio 1,08 .

Consul et al. (2009) memberikan secara numerik tentang pengaruh kepadatan(solidity)danjumlah sudu terhadap turbin cross-flow yang mempunyai dua atau empat sudu melaluisimulasi dengan angka Reynolds aliran yang tinggi. Turbin dengan soliditas yangrendah terjadi stallaliran dan dengan menaikkan jumlah sudu maka koefisien dayanaik dari 0,43 ke 0,53. Lain et al. (2010) menggunakan Commercial Solver (fluent)untuk mengetahu kinerja turbin air Darrieus. Hasil menunjukkan bahwa koefisien dayamaksimum adalah 0,33 pada perbandingan kecepatan (speed ratio)1,6 dan solititas 0,89 .

Kirke et al. (2008)menunjukkan bahwa sudut sudu yang dapat diatur posisinya menghasilkan torsi awalyang tinggi dan mempunyai efisiensi yang tinggi pula sedangkan shaking force masih dalam batas yang ditolerani.

Ketebalan sudu simetris yang dipakai pada turbin Darrieus secara teoritis oleh Winchester et al. (2009) yang memberikan bahwa semakin turun ketebalan sudu maka semakain menurun efisiensi turbin yang mana penurunan ini kecil. Hal ini juga telah dipelajari secara eksperimental oleh Kaprawi (2011) untuk ketebabalan sudu 15 s.d 30\% dari chord dari airfoil yang mana efisiensi semakin kecil untuk tebal semakin rendah. Efisiensi tertinggi yang dicapai adalah untuk sudu NACA 0015 yaitu $11,5 \%$. Untuk sudu yang tidak simetris (cambered airfoil) dari kedua penulis diatas menunjukkan efisiensi yang lebih kecil yaitu sekitar 7\%.(Kaprawi,2012).

\section{Turbin Double Spherical}

Turbin Double spherical adalah salah satu bentuk model turbin Cross Flow Water Turbine (CFWT) hasil dari pengembangan Turbin Darrieus dengan runner berbentuk bola (Spherical) yang kemudian diparallel sehingga menjadi Double Spherical. Turbin Double Spherical terdiri dari dua buah turbin shperical yang disusun parallel. Masingmasing turbin memiliki ukuran yang sama, yaitu 3 sudu dengan penampang hydrofoil yang dipasang tegak sejajar dengan poros turbin. Berikut gambar dari turbin Double Spherical.
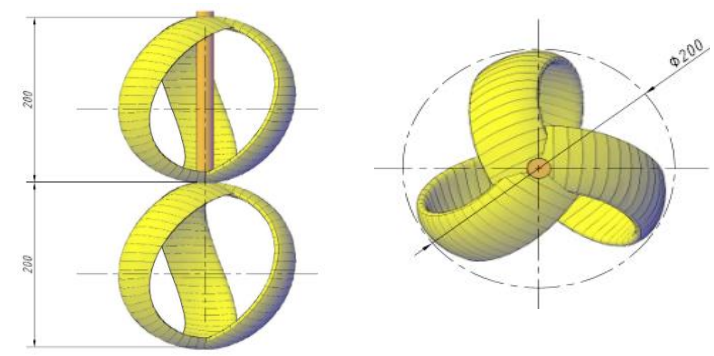

\section{Gambar 1.2 Model turbin double spherical}

(Sumber: Aldi dkk, 2018)

\section{Metode Penelitian}

Perancangan turbin Spherical terdiri dari perancangan bentuk runner, bilah sudu, pemegang turbin dan ukuran poros, dengan 
menggunakan parameter bentuk turbin Sphericalhydrofoil NACA 0016 yang sudah ada dengan bentuk Sphericalhelix NACA 0016dengan sudut putar $30^{\circ}$ dengan double runnerProses pembuatan turbin Spherical menggunakan bahan fiberglass dengan diameter turbin $25 \mathrm{cmpanjang}$ line chord dan jarak antar sudu membentuk sudut $120^{\circ}$. Model turbin Spherical menggunakan basis NACA 0016. Untuk pembuatan diperlukan bahan gerinda untuk memotong membentuk sudu turbin, kikir, amplas untuk melakukan finising yang selanjutnya dilakukan pengecetan.

\section{a. Tahap Perancangan Turbin Dimensi Turbin}

Dimensi turbin double spherical terdiri dari dua buah turbin spherical dengan panjang line chord $90 \mathrm{~mm}$ dan berdiameter $250 \mathrm{~mm}$, dimensi tersebut sudah disesuaikan dengan alat uji kinerja turbin laboratorium teknik koversi energi.

Perancangan dimensi Turbin double spherical yaitu dua buah turbin spherical dengansudut $30^{\circ}$ menggunakan basis NACA 0016.
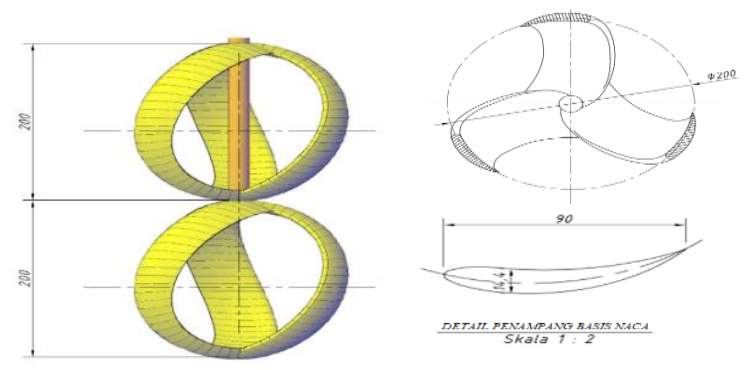

\section{Gambar 2.1 Turbin Double Spherical dengan sudut putar $30^{\circ}$}

\section{b. Pemilihan Material Turbin}

Bahan yang digunakan untuk pembuatan model turbin Spherical memiliki kriteria antara lain yaitu ringan, memiliki kesamaan ukuran dan bentuk ditiap sudunya sehingga lebih baik jika proses pembuatan menggunakan sistem cetak, tahan korosi, kuat,tidak meresap air. Berdasarkan kriteria tersebut maka dipilih bahan fiberglass dikarenakan memenuhi kriteria yang ada dibandingkan dengan bahan lainya.

\section{c. Tahap Perancangan Alat Penunjang Saluran Uji}

Saluran Uji adalah sebuah model saluran air yang digunakan atau yang difungsikan sebagai media uji potensi air untuk menguji performance atau kinerja dari turbin air. Saluran Uji di laboratorium teknik konversi energi berbentuk elips dengan spesifikasi antara lain:lebar saluran $(l)=40$ $\mathrm{cm} ;$ Kedalamansaluran $(\mathrm{z})=60 \mathrm{~cm}$.

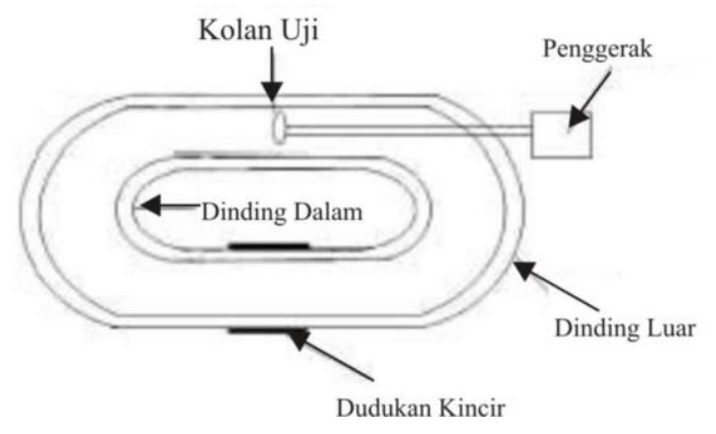

Gambar 2.2 Saluran Uji

\section{Hasil dan Pembahasan}

Rancangan turbin Spherical dan double spherical yang telah dibuat dengan sudut putar $30^{\circ}$ berbasis NACA 0016 dapat dilihat pada gambar 4.1 kedua turbin memiliki diameter yang sama yaitu $25 \mathrm{~cm}$. Dan memiliki panjang linechord $9 \mathrm{~cm}$ dengan sudut putar yang sama yaitu $30^{\circ}$

\section{a.Data Hasil Pengujian Turbin}

Pengujian turbin Spherical dan double spherical menggunakan 2 turbin dengan sudut putar yang sama, yaitu $30^{\circ}$ baik pada turbin spherical (T1) dan Double spherical (T2).

Parameter pengukuran meliputi putaran turbin (n), gaya yang dihasilkan dari pembebanan pada turbin (m), ketinggian air sebelum melewati turbin $\left(\mathbf{y}_{1}\right)$, ketinggian air setelah melewati turbin $\left(\mathbf{y}_{2}\right)$, tinggi tekan air sebelum turbin $\left(\Delta \mathbf{h}_{\mathbf{1}}\right)$, tinggi tekan air setelah turbin $\left(\Delta \mathbf{h}_{\mathbf{2}}\right)$, dan selisih antara $\Delta \mathbf{h}_{\mathbf{1}}$ dan $\Delta \mathbf{h}_{\mathbf{2}}$ yaitu $\left(\Delta \mathbf{h}_{\mathbf{1}}-\Delta \mathbf{h}_{\mathbf{2}}\right)$.

Data hasil pengujiandigunakan untuk menghitung Torsi $(\mathbf{T})$, Head Total $\left(\mathbf{H}_{\mathbf{T}}\right)$, Debit aliran (Q), Daya Hidrolik (Ph), Daya

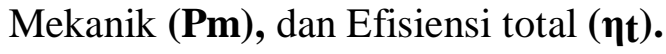


Perhitungan dapat dilihat dibawah ini :

Putaran Turbin (n) $=183 \mathrm{rpm}$

Massa beban $(\mathrm{m}) \quad=0,025 \mathrm{~kg}$

Head masuk turbin $\left(\Delta \mathrm{h}_{1}\right)=0,0373 \mathrm{~m}$

Head keluar turbin $\left(\Delta \mathrm{h}_{2}\right)=0,056 \mathrm{~m}$

Selisih head $(\Delta \mathrm{h}) \quad=0,0187 \mathrm{~m}$

Percepatan Grafitasi $(\mathrm{g})=9,806 \mathrm{~m} / \mathrm{s}^{2}$

\section{Data Hasil Pengujian}

\begin{tabular}{|c|c|c|c|c|c|c|}
\hline \multicolumn{7}{|c|}{ Turbin Double Spherical, VS kecepatan aliran $=1,2 \mathrm{~m} / \mathrm{s}$} \\
\hline beban & $\mathrm{T}(\mathrm{Nm})$ & $\mathrm{HT}(\mathrm{m})$ & $\mathrm{Q}\left(\mathrm{m}^{3 / \mathrm{s}}\right)$ & PM (Watt) & PH (Watt) & $\eta \mathrm{T}(\%)$ \\
\hline 0 & 0 & 0,07 & 0,043488 & 0 & 29,851239 & 0 \\
\hline 1 & 0,073545 & 0,0613 & 0,059469 & 1,4086809 & 35,747494 & 3,940643 \\
\hline 2 & 0,102963 & 0,0507 & 0,07444 & 1,9505997 & 37,008892 & 5,270624 \\
\hline 3 & 0,14709 & 0,0533 & 0,07106 & 2,7557802 & 37,14045 & 7,419889 \\
\hline 4 & 0,191217 & 0,0556 & 0,067931 & 3,5625002 & 37,036848 & 9,6188 \\
\hline 5 & 0,235344 & 0,0523 & 0,072379 & 4,3353503 & 37,119823 & 11,67934 \\
\hline 6 & 0,29418 & 0,0617 & 0,05883 & 5,3268153 & 35,593855 & 14,96555 \\
\hline 7 & 0,323598 & 0,0633 & 0,056199 & 5,7240172 & 34,883999 & 16,40872 \\
\hline 8 & 0,367725 & 0,0633 & 0,056199 & 6,3121222 & 34,883999 & 18,09461 \\
\hline 9 & 0,411852 & 0,0633 & 0,056199 & 6,9833625 & 34,883999 & 20,01881 \\
\hline 10 & 0,44127 & 0,07 & 0,043488 & 7,389802 & 29,851239 & 24,75543 \\
\hline 11 & 0,470688 & 0,0717 & 0,03962 & 7,6361283 & 27,856242 & 27,41263 \\
\hline 12 & 0,485397 & 0,0687 & 0,046229 & 7,569928 & 31,1433 & 24,30701 \\
\hline $\begin{array}{r}\text { Karakte } \\
\text { turbin d } \\
\text { m/sTu }\end{array}$ & $\begin{array}{l}\text { ik Torsi t } \\
\text { gan Kece } \\
\text { in Double }\end{array}$ & $\begin{array}{l}\text { ladap I } \\
\text { an Alir } \\
\text { herical }\end{array}$ & 12) & 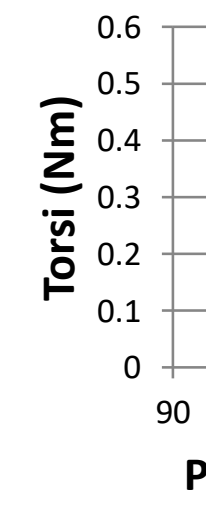 & to 130150170 & - T 2 \\
\hline
\end{tabular}




\section{Gambar 2.3 merupakan kurva karakteristik torsi terhadap putaran Turbin Double spherical (T2).}

Gambar 2.3 merupakan kurva karakteristik torsi terhadap putaran Turbin Double spherical (T2), pada kecepatan aliran 1,2 $\mathrm{m} / \mathrm{s}$. Sebagai variabel pengujian, turbin diuji dengan kecepatan aliran 1,2 $\mathrm{m} / \mathrm{s}$ dengan variasi beban . Gambar 4.3 menunjukan nilai torsi yang selalu bertambah, berbanding lurus dengan penambahan beban dan berbanding terbalik dengan nilai putaran turbin. Nilai torsi terbesar pada Turbin Double Spherical (T2) adalah 0,485397 pada putaran $149 \mathrm{rpm}$.

\section{Karakteristik Daya Mekanik terhadap Putaran Turbin dengan Kecepatan Aliran 1,2m/s Turbin Double Spherical} (T2)

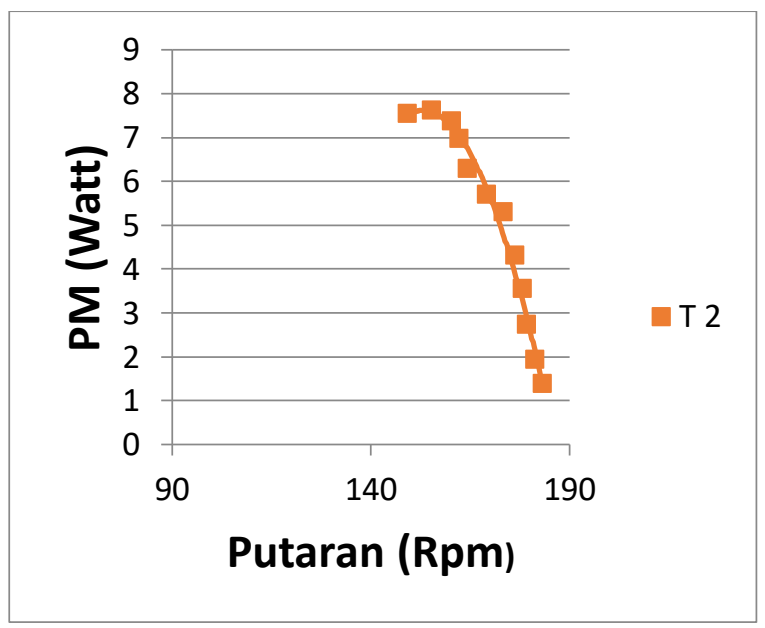

\section{Gambar 2.4 merupakan hasil pengujian turbin Double Spherical (T2)pada kecepatan aliran 1,2 m/s dengan variasi pembebanan.}

Gambar 2.4 menunjukan bahwa penambahan beban pada turbin dapat mempengaruhi putaran turbin. Semakin besar pembebanan yang diberikan pada turbin, maka putaran turbin mengalami penurunan kemudian berhenti. Perpotongan antara putaran turbin dan daya mekanik menghasilkan suatu kurva parabola dimana semakin besar penambahan beban yang diberikan pada turbin maka daya mekanik yang dihasilkan turbin semakin besar sampai mencapai titik puncak tertentu kemudian turun. Titik puncak tersebut merupakan titik optimum turbin dapat menghasilkan daya mekanik terbesar. Titik puncak turbin Double Spherical (T2) menghasilkan daya mekanik sebesar 7,6361283Watt pada putaran $155 \mathrm{rpm}$.

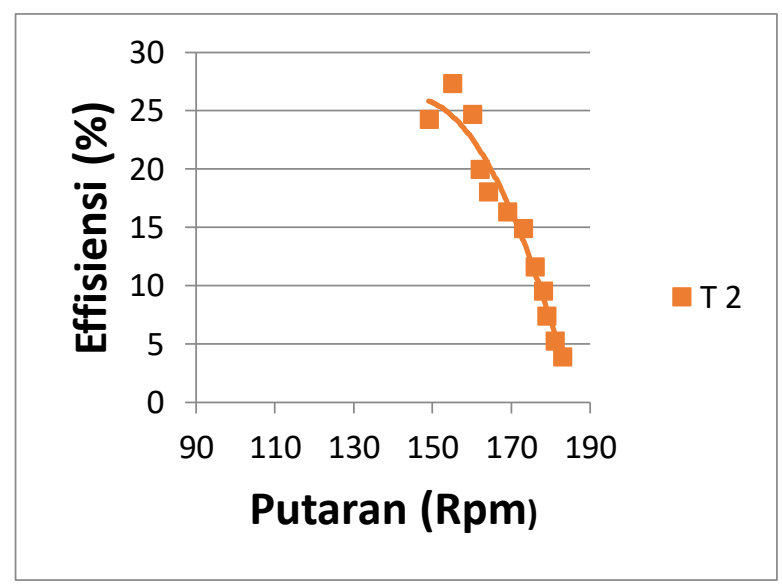

merupakan kurva karakteristik efisiensi terhadap putaran turbin Double Spherical (T2), pada kecepatan aliran 1,2 m/s. Sebagai variabel pengujian, turbin diuji dengan kecepatan aliran $1,2 \mathrm{~m} / \mathrm{s}$ dengan variasi beban. Penambahan beban turbin berpengaruh terhadap putaran turbin dan efisiensi turbin. Putaran turbin mengalami penurunan saat turbin diberi penambahan beban. Sedangkan semakin besar beban yang diberikan maka efisiensi turbin akan semakin besar sampai mencapai maksimum kemudian mengalami penurunan. Titik maksimum tersebut menunjukan titik optimum kinerja turbin karena menghasilkan efisiensi turbin terbesar Nilai efisiensi maksimum pada turbin Double Spherical (T2), adalah $27,41263 \%$ pada putaran $155 \mathrm{rpm}$.

\section{Kesimpulan}

Dari keseluruhan proses "Pembuatan turbin Double Spherical sebagai upaya memperbaiki kinerja Turbin Spherical “ dapat disimpulkan bebearapa hal antara lain: 
1. Spesifikaasi Turbin Double Spherical berbasis NACA 0016 dengan sudut putar $30^{\circ}$ adalah sebagai berikut:

a. Diameter runner $250 \mathrm{~mm}$

b. Jumlah runner 2 buah

c. Panjang poros turbin $700 \mathrm{~mm}$

d. Tebal NACA $14,4 \mathrm{~mm}$

e. Bahan runner terbuat dari Fiber

2. Hasil perbaikan kerangka uji turbin dengan menambah jumlah runner yang dipasnag secara paralel

3. Hasil kinerja turbin Double Spherical helix dengan sudut putar 30 pada kecepatan aliran $1,2 \mathrm{~m} / \mathrm{s}$ dan $1,4 \mathrm{~m} / \mathrm{s}$ yaitu:

a. Berdasarkan grafik Karakteristik Torsi terhadap Putaran pada kecepatan aliran $1,2 \mathrm{~m} / \mathrm{s}$ menghasilkan nilai torsi terbesar pada putaran $155 \mathrm{rpm}$ sebesasr $0,47069 \mathrm{~kg}$.

b. Berdasarkan grafik Karakteristik Daya Mekanik terhadap Putaran pada kecepatan aliran $1,2 \mathrm{~m} / \mathrm{s}$ menghasilkan nilai daya mekanik terbesar pada putaran 157 rpm sebesar 7,734659Watt.

c. Berdasarkan grafik Karakteristik Effisisiensi terhadap Putaran pada kecepatan aliran 1,2

d. $\mathrm{m} / \mathrm{s}$ menghasilkan nilai effisiensi tebaik pada putaran $157 \mathrm{rpm}$ sebesar $27,76634 \%$.

4. Turbin double spherical helix dengan kecepatan $1,2 \mathrm{~m} / \mathrm{s}$ dan pemberian energi yang sama menghasilkan daya mekanik sebesar 7,73466 Watt pada putaran $157 \mathrm{rpm}$ untuk kecepatan 1,2 $\mathrm{m} / \mathrm{s}$. Sedangkan turbin spherical helixdengan kecepatan dan pemberian energi yang sama dengan turbin double spherical helix menghasilkan daya mekanik sebesar 5,54235 Watt dengan putaran 120 rpm untuk kecepatan 1,2 m/.

\section{Daftar Pustaka}

Atmaja, Bima Arif,dkk 2015

Rancang Bangun Turbin Aliran

Silang dengan Runner

BerbasisBentuk Spherical. Tugas

ahir. Semarang Jurusan Teknik Mesin Polines.

Fajar Muhammad,dkk.2013. Penerapan

Kincir air Bergenerator sebagai Sumber Energi Listrik di Desa Djewatah. Program Kreativitas Mahasiswa.Semarang

Gunadi.2010.Fiberglass.http://www.crayonp edia.org/mw/BAB_12_Fiberglass_Gunadi.

(12 juni 2014)

Hatomi, Fasri.2011. Analisis CFD Turbin

Pembangkit Listrik Tenaga Arus

Laut Pada Kapasitas 1,2 KW. Skripsi.Depok: Program Studi Teknik Mesin UI.

Kaprawi 2011. Pengaruh Geometri Sudu dari turbin air Darrieus Terhadap Kinerjanya.Prosiding Seminar Nasional AvoER ke -3 ISBN:979587-395-1. Palembang

Lukmanto,Djoko.2012.

http://.slideshare.net/gilagilaan/Turbin Air-2. 12 juni 2014

Nishi, Yasuyuki, dkk. 2015. "Study on

Undershot Cross-flow Water Turbine with StraightBlades "International Journal of Rotating Machinery Volume 2015,Nomor 817926, Jepang.

Paraschiviouiu I.2002. Konsep Turbin Aliran Silang. USU InstutionalRamani, K. V., 1992, Rural electnEccation and rurar development, rural electrification Guide book for Asia \& Pacific, Bangkok.

Sahim, Kaprawi,dkk.2014. "Experimental Study of Darrieus-Savonius Water Turbine with Deflector. Effect of Deflector on the Performance International Journal of Rotating Machinery. Volume 2014, Nomor 203100. 